\title{
Academic Dishonesty in Ethiopian Higher Education and Its Implication for Corruption
}

\author{
Solomon W. Feday \\ Dire Dawa University College of Law, Dire Dawa, Ethiopia \\ Email: solefw@gmail.com
}

How to cite this paper: Feday, S. W. (2017). Academic Dishonesty in Ethiopian Higher Education and Its Implication for Corruption. Beijing Law Review, 8, 10-20. https://doi.org/10.4236/blr.2017.81002

Received: December 24, 2016

Accepted: February 21, 2017

Published: February 24, 2017

Copyright $\odot 2017$ by author and Scientific Research Publishing Inc. This work is licensed under the Creative Commons Attribution International License (CC BY 4.0).

http://creativecommons.org/licenses/by/4.0/

\section{(c) (i) Open Access}

\begin{abstract}
*
Academic dishonesty is a fundamental issue for the academic integrity of higher education institutions. Higher education institutions are places where citizens are prepared for a diverse need of life and societal issues. Hence, for long time, university students were not only a pride for their family, but for all the vicinity. They were respected and were models for high school students. Moreover, the society expects very high academic integrity. However, against these social values, academic dishonesty has reached alarming proportions in Ethiopian higher education institutions. New forms of dishonesty such as cheating, plagiarism and other forms of dishonesty are challenges of the requirement of academic honesty and integrity in higher education institutions today. Students' access to modern technologies, such as mobile phones, iPods, internets, scientific calculator has broadened the ways by which students can achieve the goal of dishonesty. Therefore, this article will explore the challenges of academic dishonesty in our higher education and it's far reaching implications for corruptions. In doing so, the paper will explore the mode of academic dishonesty and suggests systematic and comprehensive efforts to promote integrity and prevent dishonesty, especially compatible with the advancement of technology.
\end{abstract}

\section{Keywords}

Academic Dishonesty, Higher Education Institutions, Corruption, Quality Education

\section{Introduction}

This paper is motivated by a collective belief that academic dishonesty in higher education institutions threatens our social fabric and, consequently our profes-

\footnotetext{
*The draft version of a part of this paper was presented at the " $3{ }^{\text {rd }}$ National Conference on Quality of Education" organized by the Ethiopian Teachers Association in June 2015, Adama, Ethiopia. I am grateful to the participants for giving me their insightful and empirically informed comments.
} 
sion, as educators we must seek to understand the determining factors, and discusses the possible solutions.

Though it difficult to prove, there is a growing perception and empirical evidences that academic dishonesty in all levels of our educational institution is on the rise. To the dismay of the society most specifically, for us (teachers), new technologies broaden the horizon of academic dishonesty and some teachers are caught for being accomplice to this evil act. Academic dishonesty has reached alarming proportions in all higher institutions, creating widespread cynicism and an erosion of public trust. The root of the problem can be found in our schools, where academic dishonesty is rampant (Bachore, 2014).

Higher education institutions are places where students are prepared for a diverse need of life and societal issues. For long time, university students were not only a pride for their family, but for all students of the neighborhood. They were respected and were a model for high school students. In this regard, the public expected fairness, honesty and impartiality from higher education institutions. Moreover, the society expects very high academic integrity. However, against these social values, academic dishonesty has reached alarming proportions in our higher education institutions, creating widespread cynicism and an erosion of trust (Ibid).

Perceived and revealed cases of academic dishonesty are unmasking an underlying monster of dishonesty in the academy that could eat the very fabric of society (Kasozi (n.d). Moreover, academic dishonesty is the worst form of corruption which is more severe than many other forms of corruption. Higher institutions might end up producing corrupt, less competent and unethical manpower.

Dishonesty or deceptions that enhance grade on assignment or a course grade are becoming common in the teaching learning processes. New forms of dishonesty, plagiarism and other forms of dishonesty are challenges of the requirement of academic honesty and integrity in higher education institutions. Students' access to modern technologies, such as mobile phones, iPods, internets, scientific calculator has broadened the ways by which students can achieve the goal of dishonesty (Jones, 2001 \& 2011). Academic dishonesty, with Internet plagiarism as one of the most common forms, is a concern on higher education institutions more than ever before. A review of the literature validates these concerns (Donald L. McCabe, 2003).

The prevalence of academic dishonesty is against the public expectation of fairness, honesty and impartiality from our higher education institutions. According to some researches, Federal Ethics and Anti-Corruption Commission (here in after referred as FEACC (2013) and Plummer (2012) indicates that to the dismay of the academic community, some lecturers and other instructors in higher education systems are being caught in action while collaborating with cheaters. Such action is changing the perception of the public that negatively affect one of the most dignified profession-teaching. The cumulative effect of academic dishonesty is far reaching. It will not end in the school but will repeat it- 
self in the work place. In his assessment of the literatures on academic dishonesty Gillespie (2003) concluded that, there is a positive correlation between academic dishonesty and work place dishonesty/corruption.

Therefore, this paper will explore the challenges of academic dishonesty in our higher education and it's far reaching implications for corruptions. Accordingly, the paper is structured in six major sections including the introduction and conclusion. Section one covers the introductory remarks, definition of academic dishonesty and perception by faculties and students. Section two, seeks to address the prevalence of academic dishonesty in higher education institution, including the frequency in which it is engaged, how teachers and students perceived it, and what causes it.

In section three, the paper will look at real-life situations and outcomes regarding academic and workplace dishonesty. In section four and five, discuss why academic dishonesty is the worst form of corruption, its link with work place dishonesty/corruption, its implication for corruptions. This last section of the paper will conclude by describing what methods have been looked at to discourage students from engaging in academically dishonest manner.

\subsection{Definition and Forms of Academic Dishonesty}

Academic dishonesty has been defined in many ways. In his 1964 study, Bowers described academic dishonesty as students engaging in dishonest behaviors not limited to activities such as plagiarizing and fraudulence.

According to Jones (2001 \& 2011), academic dishonesty is any deceitful or fraudulent attempt to evade rules, standards, practices, customs, and norms to gain an unfair advantage or to protect someone who has done so. Bowers (1964) defined academic dishonesty as "students engaging in dishonest behaviors not limited to activities such as plagiarizing and cheating".

For Moeck (2002) academic dishonesty is the abuse of academic materials by destroying or altering portions of content. This could include cheating off another student's test during an exam, plagiarizing by not citing the author, or damaging equipment so other students would not be able to use it (such as taring parts of a book in the library which is a common practice in many libraries of Ethiopia).

According to professor Kasozi (n.d), academic dishonesty is all selfish acts that are contrary to the just and equitable delivery of higher education. Like other forms of the same evil, it arises from the moral impurity of the individual who deviates from the expected behavior ideal and, instead, behaves in a selfish and repugnant way. Academic corruption includes but is not limited to; plagiarism, fabrication, deception, cheating, bribery, sabotage, professional misconduct on the part of tutors, impersonification on the part of students, the use of institutional authority or name for personal gain in the process of higher education delivery and reception (ibid).

Hence, academic dishonesty is any behavior on the part of a student that results in that student's or any other students' giving or receiving unauthorized as- 
sistance in an academic exercise or receiving credit for work which is not their own.

In Ethiopia, academic dishonesty, in most cases is being manifested in the form of cheating in exams and plagiarism (papers and assignments) (Bachore, 2014: p. 1062). This could include behaviors such as dishonesty off another student's test during an exam, plagiarizing by not citing the author, or damaging equipment so other students would not be able to use it (such tarring parts of the book, writing on it, hiding, stealing (a lecturer from one university was caught stealing books from Addis Abaa University Kennedy Library to satisfy his addiction and sentenced for two years imprisonment). In his study Plummer (2012), added fraudulent practices in examinations including Impersonation. He also noted that, to the dismay of the academic community some teachers are also involved in allowing both individual and group dishonesty in examinations, assistance from invigilators, leaking exam questions, giving grade in exchange of sex (p. 96). In Dire Dawa University, this year alone two students were caught taking exam for other students, fifteen law graduating students were caught plagiarizing in their term paper and 2013 one student was caught plagiarizing in his dissertation.

\subsection{Perceptions of Academic Dishonesty: Students and Faculty}

While dealing with academic dishonesty or evaluating ways to prevent it, it is useful to examine how it is perceived by the academia and the students. The way a university system, its' students, professors and faculty, view academic dishonesty may have a great deal to do with how often it occurs and how it can be prevented. The first thing to look at is what constitutes academic dishonesty $s$ in the eyes of students. In a study by Greene \& Saxe (1992), students perceived dishonesty and other forms of academic dishonesty to be normal behavior for students. However, when they asked "Is it wrong to cheat" (Davis, Grover, Becker, \& McGregor, 1992), around 90\% of the student answered yes. This clearly shows that students know that dishonesty is wrong. However, when these authors looked at the evidence of the actual frequency of dishonesty, they found quite the opposite: of the $90 \%$ students who think academic dishonesty is wrong, $76 \%$ of them reported engaging in academically dishonest behaviors. This reveals that dishonesty is not associated with lack of awareness.

In another study (Jones, 2001 \& 2011), several students had difficulty identifying what was and what was not academic dishonesty. Overall, only $50 \%$ or more of the students correctly identified nine of the scenarios correctly. The top scenarios identified were (a) turning in another person's assignment as your own assignment (100\%), (b) cutting and pasting a paper together using online materials without appropriate citations (92\%), (c) purchasing a paper from a research service or downloading one from the Internet (75\%), and (d) delivering an oral/ digital presentation based on information copied directly from the Internet without appropriate citations (75\%). The study by the FEACC indicated that during evaluation, university students believe that academic factors less influence the 
assessment of students on the contrary ethnicity, religious affiliation, gift from students etc., are influencing the assessment of students' performance.

\section{Prevalence of Academic Dishonesty}

Academic dishonesty is a global concern. According to numerous studies, dishonesty is more prevalent than ever and actions need to be taken by universities to educate students about academic integrity (Gillespie, 2003). Studies show that the global level of academic dishonesty are as high as $80 \%$ when students selfreport and faculty members as having witnessed academically dishonest behaviors in their students (Morales, 2000). With numbers this high, whether or not academic dishonesty is on the rise, it is a serious concern that the education system needs to address.

In Ethiopia too, academic dishonesty is rising in an alarming rate (Bachore, 2014). One study (Tefera \& Kinde, 2009) reported that the perception and actual encounter of teachers of Addis Ababa University and Jimma University School of Business and Economics and education faculty found that (7.2\%) respondents reported that they did not encounter students engaged on academic dishonesty, (14.5\%) encountered students engaged on academic dishonesty s once, (14.5\%) encountered twice, (30.1\%) encountered 3 - 5 times, (4.8\%) encountered $6-10$ times and $(25.3 \%)$ encountered more than ten times. According to this finding, only $7.2 \%$ of teachers respond that they did not encounter with students engaged on academic dishonesty while more than $89 \%$ percent of the respondent told the researchers that the encounter students engaged on academic dishonesty. In their similar topic, Tefera \& Kinde, (2010) found that about (96.4\%) of the respondents(students) were engaged at least once in one form of assignmentrelated dishonesty while $(82.1 \%)$ and $(82.0 \%)$ respondents reported they were involved at least once or more on research and exam-related dishonesty s, respectively. According to their finding the respondents admit that they engaged in high level of assignment-related academic dishonesty followed by research and exam-related academic dishonesty.

The findings of Tefera \& Kinde $(2009,2010)$ clearly indicate that the prevalence rate of academic dishonesty in Ethiopian Universities is as high as $84 \%$. The other research (Plummer, 2012), found a depressing report that teachers and administrative organs also involve in allowing both individual and group dishonesty in examinations. Moreover, most consider students not to be judged fairly and report that teachers do not respect equality of students regarding religion, sex, or ethnic origin. $25 \%$ consider a student's political affiliation to be a factor influencing the assessment of work; $20 \%$ consider the payment of gifts to be a factor in obtaining a degree; and $12 \%$ report political affiliation to be a factor. In addition, $33 \%$ report that staffs favor their relatives; and $27 \%$ say the staff members selectively leak questions. School staffs report low levels of conflict between teachers and students over grades. When it occurs, the main complaints are that some students are favored more than others, including by receiving advance information about exams. The other forms of academic dishonesty, is 
fraudulent over scoring of examination papers.

Generally, dishonesty is becoming very worrisome, especially when teachers the guardian of high integrity and student's future (teacher's judges, engineers, chief economist, etc.) are engaged in academic dishonesty. Dishonesty in exam, coping of term papers and dissertations from our universities is copy of the past. Shamelessly some students are not taking their time even to think who the original writer is. That is why many submit their dissertations by copy pasting their advisors' work. Some paid for specialized writers of term papers and dissertations in and around universities, who are known as "ghostwriters" providing their services to a wide clientele (Mebrtu, p, 1062). What is more disappointing as once Addis Neger Gazetea wrote, young university lecturers are among such ghostwriters.

\section{Why Academic Dishonesty Persists? Causes of Academic Dishonesty}

There are many reasons for engaging in academically dishonest behavior. A number of studies have identified some of the reasons why students choose to engage in academic dishonesty. Some students feel pressure to get better grades, and some students struggle academically and feel that dishonesty is their only path to any kind of success. Some students feel that engaging in academically dishonest behaviors is not a serious offense, and others do not realize that they have broken any rules.

In 1941, after finding that $23 \%$ of the students he studied had engaged in academically dishonest behavior, Drake concluded that less intelligent students appear to cheat more than more intelligent students. He also felt that because the students with lower academic skills cheated the most, they did so because of a need to get higher grades. According to him the principal reason for dishonesty is to get high grade. On the other hand, when Davis et al. (1992), asked the reasons for dishonesty many reasons came up. Some students reported that they were helping a friend; some did not feel that it was wrong, and some felt pressure from their peers to cheat. Others felt a great amount of pressure to succeed in an academic setting to ensure employment after the university. One of the more obvious reasons a student might be inclined to cheat is for better grades. In a recent article, Moeck (2002) stated, "With tremendous pressure and competition for grades, some (students) will cheat or plagiarize to maintain a high GPA, which can please parents, result in selection to school leadership roles, and impress corporate recruiters" (p. 484).

For McCabe \& Pavela (2000), large class size and where there teacher and student barley contact, will also lead to academic dishonesty. Professor Kasozi (n.d), on his part, forward three major reasons why academic dishonesty persists and kept on the rise. First the increased demand for higher education increases the struggle to get admissions. In most of Africa, the demand has been increasing steadily to fill an education vacuum created by earlier neglect of access at all levels of education. The aggressive competition to access higher education insti- 
tutions empowers all owners of higher education facilities with demanded products that can be sold corruptly by unethical sellers. Secondly, higher education is vital for accessing good jobs. Most sought for jobs demand higher education qualifications especially the terminal degrees of masters and doctorates. Lastly, social cleavages of nations are always reflected, or represented, in most of a country's institutions. It is naïve for us to expect our universities to be clean when our society is perceived to be corrupt. For Niels (n.d) the decline in student values is the sole reason for the reported rise in dishonesty behavior.

A question that is not asked very often is what motivates people to plagiarize and why others resist it. One possible answer is that academic corruption is both a consequence and a symptom of the growing importance of higher education in the world. Because education, research, and publication are connected to valuable goods of society, such as money and prestige, it should not be surprising that some people decide to take shortcuts to get academic credentials that will provide access to those rewards.

Academic corruption is certainly more visible now than, let's say, decades ago, and academic knowledge exercises an increasingly important influence in most societies. Academic corruption's surreptitious nature makes it almost impossible to track the extent of the problem, not to mention benchmark today's corruption against fraud committed a century ago in order to know if it is indeed growing and to what extent. It is easier to measure the perception of corruption, something that the organization Transparency International recognized a couple decades ago. Still, many people are convinced that actual corruption is on the rise. Some claim that the Internet has make plagiarism easier because today it just takes a few keystrokes to copy and paste a few pages or a complete dissertation what Jones (2001 \& 2011) call "term papers Mill".

As a warning to those who don't want to bother attending a university to earn their degree but prefer buying their diploma and transcripts, there is a small but efficient number of people and agencies identifying diploma mills and disseminating information. Some countries and institutions now have high-tech test rooms to anticipate and neutralize high-tech and low-tech dishonesty strategies on admissions exams. Employers are outsourcing the screening of employee credentials.

One recent study (Jones, $2001 \& 2011$ ) summarized the reasons students engaged in academic dishonesty-cheating and plagiarism - varied, but as commonly understood, the over-riding reason was performance (92\%), procrastination (83\%), and too busy, not enough time to complete assignment or study for test (75\%).

Similarly, studies suggest that the causes of academic dishonesty in the Ethiopian higher education institutions are attributable to various reasons (Tefera \& Kinde, 2010; FEACC, 2013), students reflected that "lack of commitment for mastery learning, grade motives, and lack of confidence in academia are some of the factors they perceived as adversely affecting students honest behavior in the universities." Moreover, institutional/contextual factors like unfair/biased treatment of some teachers in scoring and grading based on ethnicity, gender, and 
religion, lack of close academic contact between teachers and students as well as between students and department heads, lack of positive relationship between students and teachers, carelessness in assessment practices that are explained in terms of repeating previous exam questions as they were, lack of careful control mechanism in exam Duplication, poor compiling, and poor invigilation seriously affected the students honest behavior in their respective faculties.

\section{Why Academic Dishonesty Is the Worst Form of Corruption?}

Academic corruption is not only deadly in the short but also in the long terms. Badly trained-or untrained-professionals like doctors, architects, engineers, financial analysts; economic managers and teachers can have adverse impact on society the day they start to work (pacheo, n.d) The long-term impact of badly trained higher education graduates is catastrophic. Long term planning needs critical minds that can see through national challenges and advise society accordingly. The far reaching effects of academic dishonesty higher education institutions will produce semi-educated professionals.

Academic dishonesty is not only dangerous for the nation at large but also to the cheaters too. Especially, when caught, also coasts a carrier and reputation of the cheaters and a life time humiliation. For instance, In Germany, the former Minister of Defense, and a Vice-President of the European Parliament, resigned from their positions after plagiarism was discovered in each person's doctoral dissertation. In the UK, the London School of Economics had to address alleged plagiarism in the PhD thesis of Saif el-Islam Gaddafi, the famous son of Muhamar Gadafi. In Pakistan, over 140 lawmakers were found guilty of holding fake degrees, and in the UK, a university registrar was condemned to a suspended jail sentence after he was discovered trading fake degrees for spanking sessions.

Furthermore, in 2009, the academic community and the public were shaken by the (so called) "climate gate". The illegal interception of email correspondence between US and the UK researchers suggested the fabrication and manipulation of data in order to support the theory of human-instigated global warming. Yet after examination in each country no wrongdoing was proven. On May 2011, a report commissioned by a group of legislators in the US, known for their denial of climate change theory, was found (in large part) to be plagiarized underscoring the vulnerability of researchers and encouraging doubts about the reliability of anyone's data. In Ethiopia, the former Addis Ababa University School of law registrar was caught selling grades. In 2013 one student from Dire Dawa university school of law were suspended from graduation for plagiarism of his dissertation.

Many believe that plagiarism and other forms of academic corruption are becoming more pervasive and the examples presented above might suggest that it is true. Before panicking, it is important to consider that the academic world is expanding, hence opportunities for academic corruption as well. The number of undergraduate and graduate students has been growing in almost every country 
around the world and those who enter the system stay for a longer time. (Just consider how much time it takes to get a Ph.D.) The personal investment is greater, as is the competition. In addition, there are more countries trying to move into the "big leagues of academia," which adds even more pressure to the whole system.

Higher education and academic research have more impact on society today. Perhaps it is a consequence of being immersed in the modern knowledge economy. Most well-paid professional positions require a higher education credential (often a masters or a doctoral degree). Research has the potential to reshape the lives of millions of people, also the potential to return wealth to the researcher and prestige (and improved position in rankings) to the institution that hosts him or her. Additionally, research is often used to justify public policy. The stakes have become much higher.

\section{Implications for Quality of Education}

Academic dishonesty disproportionally affects the quality of education. Academic criteria will be ignored. Academic dishonesty profoundly damages the quality of education, in the end the capacity of institutions both public and private to deliver quality service. This is because competency in service cannot be achieved without competitive learning atmospheres. Academic dishonesty is also against the objectives of higher education policy (Higher Education Proclamation, 2009: Art. 4), partly states that

"prepare knowledgeable, skilled, and attitudinally mature graduates in numbers with demand-based proportional balance of fields and disciplines so that the country shall become internationally competitive; promote and enhance research focusing on knowledge and technology transfer consistent with the country's priority needs... and rational discourse and are free from biases and prejudices ... design and provide community and consultancy services that shall cater to the developmental needs of the country ... Promote and uphold justice, fairness, and rule of law in institutional life..."

It's obvious that an academically dishonest student and gradates will never fulfill such a high call. Instead academic dishonesty leads to corruption in the work place.

What are the penalties for cheating anyway?

Most often, the penalties for cheating are at the instructor's discretion. Depending on the severity of the breach, the penalties range from awarding an "F" (0 points) on the exam or the assignment to receiving an " $\mathrm{F}$ " grade in the course. Or giving another chance for the student to come with a genuine work (this year alone Dire Dawa university school of law give 0 marks 15 graduate students and with explicit application for mercy, the school allow them to do another task, in 2013 one student's degree was hold due to plagiarism in his dissertation. The school council forced him to write another paper for being caught, two students were awarded 0 marks for cheating final exams) in the impersonation case the committee suspended the impersonator. 


\section{Concluding Remarks}

In conclusion, from the beginning, we have said that higher education institutions are places where students are prepared for a diverse need of life and societal issues. In this regard, the public expected fairness, honesty and impartiality from higher education institutions. Moreover, the society expects very high academic integrity. However, against these social values, academic dishonesty has reached alarming proportions in our higher education institutions, creating widespread cynicism and an erosion of trust.

The paper discussed that academic dishonesty is on the rise at an alarming rate in our higher education institutions. It also discussed that the prevalence of academic dishonesty disproportionally affects the quality of education. Academic criteria will be ignored. Academic dishonesty profoundly damages the quality of education, in the end the capacity of institutions both public and private to deliver quality service. This is because competency in service cannot be achieved without competitive learning atmospheres. The reviewed literature revealed that there is a strong link between academic dishonesty and work place dishonesty. It is also against the objectives of higher education policy. For the time being, this paper recommends that as academic dishonesty has multidimensional effects, the solution also requires multi-sectoral response.

\section{References}

Bachore, M. M. (2014). Academic Dishonesty/Corruption in the Period of Technology: Its Implication for Quality of Education. American Journal of Educational Research, 2, 1060-1064. https://doi.org/10.12691/education-2-11-9

Bowers, W. J. (1964). Student Dishonesty and It's Control in College. New York: Columbia University Press.

Davis, S. F., Grover, C. A., Becker, A. H., \& McGregor, L. N. (1992). Academic Dishonesty: Prevalence, Determinants, Techniques, and Punishments, Teaching of Psychology, 19, 16-21. https://doi.org/10.1207/s15328023top1901_3

Federal Ethics and Anti Corruption Commission (FEACC) (2013). Good Governance and Ethics in Public Higher Education Institutions, Addis Ababa.

Gillespie, K. A. (2003). The Frequency and Perceptions of Academic Dishonesty among Graduate Students: A Literature Review and Critical Analysis. The Graduate College University of Wisconsin.

Greene, A. S., \& Saxe, L. (1992). Everybody (Else) Does It: Academic Cheating. Paper Presented at the Annual Meeting of the Eastern Psychological Association.

Higher Education Proclamation (2009) Proc. No. 650, Fed. Gaz., 15th Year No. 64.

Jones, L. R. (2001 \& 2011). Academic Integrity \& Academic Dishonesty: A Hand book about Cheating \& Plagiarism. Revised \& Expanded Edition, Melbourne, FL: Florida Institute of Technology.

McCabe, D. L., \& Pavela, G. (2000). Some Good News about Academic Integrity. Change, 33, 32-38. https://doi.org/10.1080/00091380009605738

Moeck, P. G. (2002). Academic Dishonesty: Cheating among Community College Students. Community College Journal of Research and Practice, 26, 479-491. https://doi.org/10.1080/02776770290041846

Morales, T. (2000). School Cheating as Social Corrosion. Christian Science Monitor, 92. 
Niels, G.J. (n.d). Academic Practices, School Culture and Cheating Behavior. Winchester: Thurston School

Plummer, J. (2012). Diagnosing Corruption in Ethiopia: Perceptions, Realities, and the Way, Forward. Washington DC: World Bank. https://doi.org/10.1596/978-0-8213-9531-8

Tefera, T., \& Kinde, G. (2009). Faculties' Perception and Responses to Academic Dishonesty of Undergraduate Students in Education, Business and Economics Ethiop. J. Educ. \& Sc., 4, No. 2.

Tefera, T., \& Kinde, G. (2010). An Exploration of Undergraduate Students' Self-Reported Academic Dishonesty at Addis Ababa and Jimma Universities, Ethiop. J. Educ. \& Sc., 5, No. 2.

Submit or recommend next manuscript to SCIRP and we will provide best service for you:

Accepting pre-submission inquiries through Email, Facebook, LinkedIn, Twitter, etc. A wide selection of journals (inclusive of 9 subjects, more than 200 journals)

Providing 24-hour high-quality service

User-friendly online submission system

Fair and swift peer-review system

Efficient typesetting and proofreading procedure

Display of the result of downloads and visits, as well as the number of cited articles

Maximum dissemination of your research work

Submit your manuscript at: http://papersubmission.scirp.org/

Or contact blr@scirp.org 